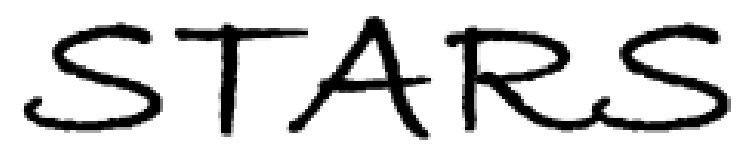

University of Central Florida

STARS

$1-1-2009$

\title{
Enhanced thermal stability and nanoparticle-mediated surface patterning: Pt/TiO2(110)
}

\author{
A. Naitabdi \\ University of Central Florida \\ F. Behafarid \\ University of Central Florida \\ B. Roldan Cuenya \\ University of Central Florida
}

Find similar works at: https://stars.library.ucf.edu/facultybib2000

University of Central Florida Libraries http://library.ucf.edu

This Article is brought to you for free and open access by the Faculty Bibliography at STARS. It has been accepted for inclusion in Faculty Bibliography 2000 s by an authorized administrator of STARS. For more information, please contact STARS@ucf.edu.

\section{Recommended Citation}

Naitabdi, A.; Behafarid, F.; and Cuenya, B. Roldan, "Enhanced thermal stability and nanoparticle-mediated surface patterning: Pt/TiO2(110)" (2009). Faculty Bibliography 2000s. 1943.

https://stars.library.ucf.edu/facultybib2000/1943

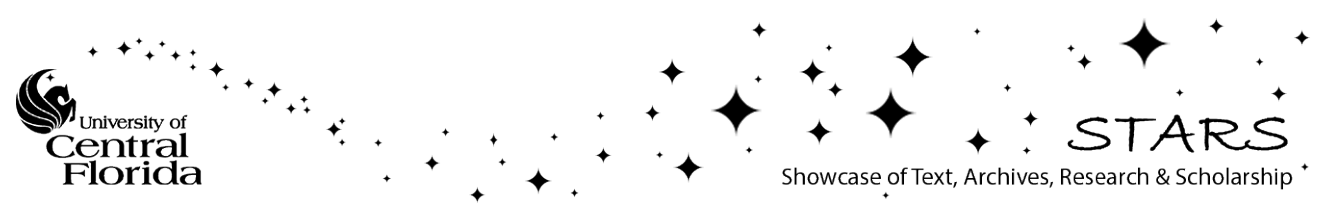




\section{Enhanced thermal stability and nanoparticle-mediated surface patterning: $\mathrm{Pt} / \mathrm{TiO}_{2}(110)$}

Cite as: Appl. Phys. Lett. 94, 083102 (2009); https://doi.org/10.1063/1.3083557

Submitted: 08 December 2008 . Accepted: 27 January 2009 . Published Online: 23 February 2009

A. Naitabdi, F. Behafarid, and B. Roldan Cuenya

\section{ARTICLES YOU MAY BE INTERESTED IN}

Formation, thermal stability, and surface composition of size-selected AuFe nanoparticles Applied Physics Letters 91, 113110 (2007); https://doi.org/10.1063/1.2784957

Local investigation of the electronic properties of size-selected Au nanoparticles by scanning tunneling spectroscopy

Applied Physics Letters 89, 043101 (2006); https://doi.org/10.1063/1.2233601

Nucleation and growth of Pt nanoparticles on reduced and oxidized rutile $\mathrm{TiO}_{2}$ (110)

The Journal of Chemical Physics 141, 214702 (2014); https://doi.org/10.1063/1.4902249

\section{Applied Physics Letters}

Mid-IR and THz frequency combs special collection

Read Now! 


\title{
Enhanced thermal stability and nanoparticle-mediated surface patterning: $\mathrm{Pt} / \mathrm{TiO}_{2}(110)$
}

\author{
A. Naitabdi, ${ }^{1}$ F. Behafarid, ${ }^{1}$ and B. Roldan Cuenya ${ }^{1,2, a)}$ \\ ${ }^{1}$ Department of Physics, University of Central Florida, Orlando, Florida 32816, USA \\ ${ }^{2}$ Nanoscience and Technology Center, University of Central Florida, Orlando, Florida 32816, USA
}

(Received 8 December 2008; accepted 27 January 2009; published online 23 February 2009)

\begin{abstract}
This letter reports (i) the enhanced thermal stability (up to $1060{ }^{\circ} \mathrm{C}$ ) against coarsening and/or desorption of self-assembled Pt nanoparticles synthesized by inverse micelle encapsulation and deposited on $\mathrm{TiO}_{2}(110)$ and (ii) the possibility of taking advantage of the strong nanoparticle/ support interactions present in this system to create patterned surfaces at the nanoscale. Following our approach, $\mathrm{TiO}_{2}$ nanostripes with tunable width, orientation, and uniform arrangement over large surface areas were produced. (c) 2009 American Institute of Physics. [DOI: 10.1063/1.3083557]
\end{abstract}

Strong metal-support interactions ${ }^{1,2}$ are believed to be a key factor determining the reactivity of heterogeneous catalysts such as Pt nanoparticles (NPs) supported on $\mathrm{TiO}_{2}$. Most of the past research efforts in this field considered vacuum evaporated, chemical vapor deposited, or electron-beam synthesized Pt NPs as model systems. Two common trends were identified: the onset of NP coalescence upon annealing below $\sim 430{ }^{\circ} \mathrm{C}$ (Ref. 3) and NP encapsulation by $\mathrm{TiO}_{x}$ compounds. ${ }^{1,2}$ Both effects were found to dramatically affect the electronic ${ }^{1}$ and catalytic ${ }^{3}$ properties of this system.

It is well known that the NP size is one of the crucial parameters determining the activity and selectivity of supported nanocatalysts. ${ }^{4-6}$ At elevated operation temperatures, the performance of industrial catalysts is strongly influenced by NP coarsening, commonly leading to catalyst deactivation. In order to minimize these undesirable effects, stable arrays of NP catalysts homogenously dispersed on a support are needed. ${ }^{7-9}$ Additionally, the structure, chemical composition, and stability of the NP support are also essential in maintaining the reactivity of supported clusters. Interestingly, the presence of the NPs can affect the stability of the support. For example, the dissolution of $\mathrm{Pt}$ during $\mathrm{O}_{2}$ reduction in an electrochemical environment was found to be reduced in the presence of Au NPs. ${ }^{10}$ Therefore, the design of a stable support-metal NP system requires a thorough understanding of the changes in the electronic, chemical, and morphological properties of the support induced by the NPs.

In this letter we will show that particle size selection and enhanced thermal stability (up to $1060{ }^{\circ} \mathrm{C}$ ) can be achieved when Pt NPs ( $\sim 3 \mathrm{~nm}$ in height $)$ are synthesized by micelle encapsulation and deposited on $\mathrm{TiO}_{2}(110)$. Furthermore, the ordered NP array achieved can be utilized to pattern the underlying substrate into $\mathrm{TiO}_{2}$ nanostripes with tunable width, orientation, and separation. This opens the possibility of tailoring the morphological structure of a catalytic support at the nanoscale level.

Self-assembled size-selected Pt NPs were synthesized by encapsulation in diblock-copolymer micelles formed by dissolving polystyrene-block-poly(2-vinylpyridine) $[\mathrm{PS}(x)-\mathrm{P} 2 \mathrm{VP}(y)]$ (with molecular weights $x=27700$ and $y$ $=4300 \mathrm{~g} / \mathrm{mol}$ ) in toluene. Subsequently, $\mathrm{H}_{2} \mathrm{PtCl}_{6} \cdot 6 \mathrm{H}_{2} \mathrm{O}$ was added to the polymeric solution at a metal salt to PS-P2VP

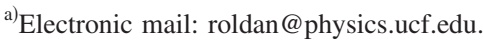

concentration ratio of 0.6 . The NP size is controlled by the length of the polymer head (P2VP) and the metal-salt/P2VP concentration ratio, while the interparticle distance is determined by the length of the polymer tail (PS). A monolayerthick film of NPs was obtained by dip coating (ex situ) a $\mathrm{TiO}_{2}(110)$ single crystal into the Pt polymeric solution. The $\mathrm{TiO}_{2}$ substrate was previously cleaned in ultrahigh vacuum (UHV) by $\mathrm{Ar}^{+}$sputtering $(1 \mathrm{keV})$ and annealing cycles at $950{ }^{\circ} \mathrm{C}$ and then exposed to air. The sample was then introduced into a UHV system (SPECS, GmbH) for chemical and morphological characterizations. The encapsulating polymer was removed in situ by $\mathrm{O}_{2}$-plasma exposure (4 $\times 10^{-5}$ mbar, $\left.95 \mathrm{~min}\right)$. Complete removal of the organic ligands was evidenced by the lack of $\mathrm{C} 1 s$ signal in X-ray photoelectron spectroscopy (XPS) measurements. Subsequently, the sample was isochronally annealed in situ in $100{ }^{\circ} \mathrm{C}$ intervals $\left(20 \mathrm{~min}\right.$ ) from 300 to $900{ }^{\circ} \mathrm{C}$, and in $10{ }^{\circ} \mathrm{C}$ intervals $\left(10 \mathrm{~min}\right.$ ) from 1000 to $1060{ }^{\circ} \mathrm{C}$. XPS (not shown) and scanning tunneling microscopy (STM) (Aarhus-SPECS) data were acquired after several thermal treatments (Figs. 1 and 2).

Figure 1 displays STM images of Pt NPs deposited on $\mathrm{TiO}_{2}(110)$ after polymer removal by atomic oxygen exposure and annealing at (a) 300 and (b) $1000{ }^{\circ}$ C. Surprisingly, neither the NP size nor their surface distribution was found to change significantly upon annealing at $1000{ }^{\circ} \mathrm{C}$ [Fig. $1(b)$. However, a decrease in the roughness of the $\mathrm{TiO}_{2}$ support (induced by the initial $\mathrm{O}_{2}$-plasma treatment) from
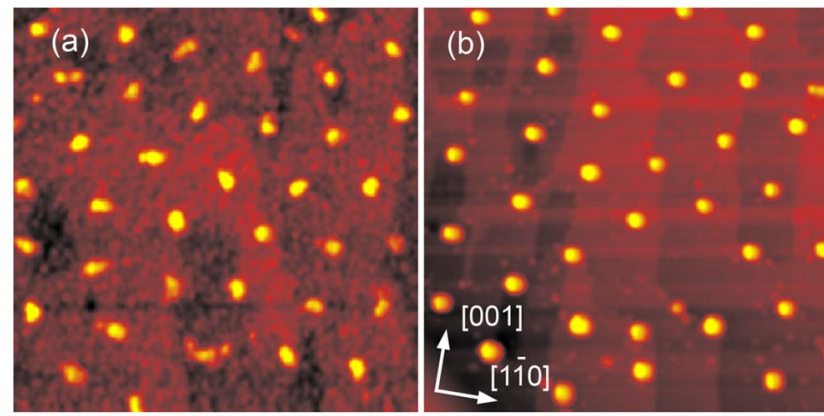

FIG. 1. (Color online) $\left(200 \times 200 \mathrm{~nm}^{2}\right)$ In situ STM images of Pt NPs deposited on $\mathrm{TiO}_{2}(110)$ after an $\mathrm{O}_{2}$-plasma treatment and annealing in UHV at (a) $300{ }^{\circ} \mathrm{C}$ for $20 \mathrm{~min}$ and (b) $1000{ }^{\circ} \mathrm{C}$ for $10 \mathrm{~min}$. 

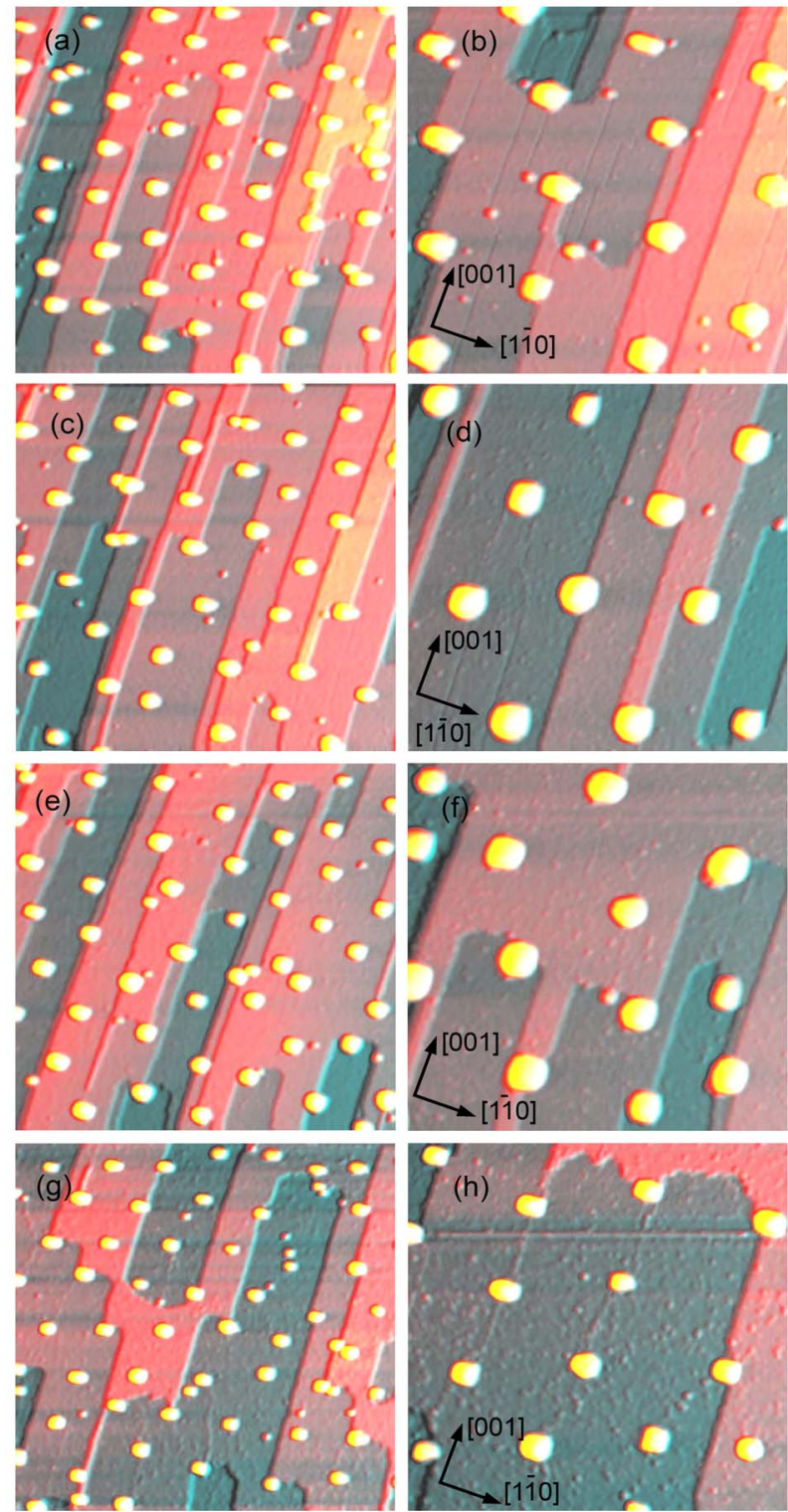

FIG. 2. (Color online) In situ STM images of Pt NPs deposited on $\mathrm{TiO}_{2}(110)$ acquired after $\mathrm{O}_{2}$-plasma and subsequent annealing for $10 \mathrm{~min}$ in UHV at [(a) and (b)] $1010{ }^{\circ} \mathrm{C}$, [(c) and (d) $] 1040{ }^{\circ} \mathrm{C}$, [(e) and (f) $] 1060{ }^{\circ} \mathrm{C}$, and $[(\mathrm{g})$ and $(\mathrm{h})]$ second $1060{ }^{\circ} \mathrm{C}$. The size of the images in the left column is $200 \times 200 \mathrm{~nm}^{2}$ and in the right column is $100 \times 100 \mathrm{~nm}^{2}$.

$0.3 \pm 0.05 \mathrm{~nm}$ after subsequent annealing at $300{ }^{\circ} \mathrm{C}$ to $0.07 \pm 0.03 \mathrm{~nm}$ at $1000{ }^{\circ} \mathrm{C}$ with a $(1 \times 2)$ surface reconstruction can be seen. Further stepwise annealing from 1010 to $1060{ }^{\circ} \mathrm{C}$ [Figs. 2(a)-2(f)] demonstrated the enhanced thermal stability and low mobility of our Pt NPs. Only upon annealing at $1060{ }^{\circ} \mathrm{C}$ for an additional $10 \mathrm{~min}$ [Figs. 2(g) and 2(h)] were small changes in the NP size and in the local NP arrangement noticed.

Figure 3 shows histograms of the (a) NP height and (b) interparticle distance obtained from the analysis of numerous STM images acquired after different in situ thermal treatments from 1000 to $1060{ }^{\circ} \mathrm{C}$. The data in Fig. 3(a) indicate that the average NP height is nearly constant up to the first annealing treatment at $1060{ }^{\circ} \mathrm{C}$ for $10 \mathrm{~min}(3.4 \pm 0.2 \mathrm{~nm})$. However, a clear increase in the width of the NP height distribution and bimodal shape is observed upon further annealing at the same temperature $\left(1060{ }^{\circ} \mathrm{C}, 20 \mathrm{~min}\right)$, with average peak heights in the distribution of 3.2 and $2.3 \mathrm{~nm}$. In
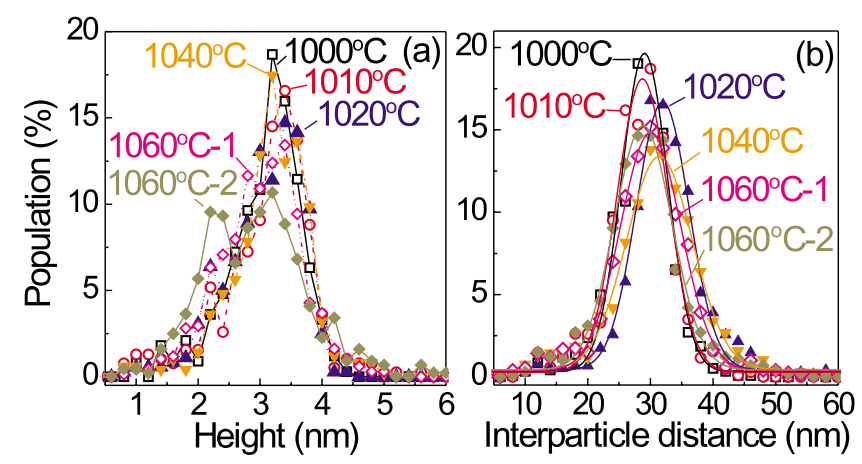

FIG. 3. (Color online) Normalized histograms of (a) NP height and (b) interparticle distance obtained from STM images acquired after isochronal annealing in $10{ }^{\circ} \mathrm{C}$ intervals $(10 \mathrm{~min})$ from 1010 to $1060{ }^{\circ} \mathrm{C}$. The lines in (a) are guides for the eyes, while the data in (b) were fitted using Gaussian curves. For each temperature, the above statistics include 300-670 NPs.

addition, the width of the height distribution increased from $0.9 \mathrm{~nm}$ at $1000{ }^{\circ} \mathrm{C}$ to $1.6 \mathrm{~nm}$ at $1060{ }^{\circ} \mathrm{C}$ (second). These effects are attributed to atomic Pt desorption rather than to Ostwald ripening, since no increase in the average number of large NPs was observed.

The nearest-neighbor interparticle distance histograms shown in Fig. 3(b) demonstrate that our initial hexagonal NP arrangement is basically preserved after high temperature annealing, with an average interparticle distance (peak of the distribution) of $30 \pm 2 \mathrm{~nm}$ from 1000 to $1060{ }^{\circ} \mathrm{C}$. If entire NPs were to desorb at high temperature, a shift in the histogram peak toward higher interparticle distances should have been observed. Significant particle mobility would have led to a broadening of the interparticle distance distribution and a corresponding reduction in the peak height. A small increase in the width (standard deviation) of the interparticle distance distribution (from $\sim 7.3 \mathrm{~nm}$ at $1000{ }^{\circ} \mathrm{C}$ to $9.1 \mathrm{~nm}$ at $1060{ }^{\circ} \mathrm{C}, 20 \mathrm{~min}$ anneal) and a decrease in its height (peak population) can be observed above $1040{ }^{\circ} \mathrm{C}$. This result might indicate a weakening of the NP-support adhesion and the consequent onset of NP mobility. Since after our second annealing at $1060{ }^{\circ} \mathrm{C}$ some smaller particles $(\sim 2.3 \mathrm{~nm})$ are present on the sample, the possibility of particle break up and local cluster mobility is more likely. Despite the observation of some local disorder, the majority of our scans still showed clear signs of a hexagonal NP arrangement up to at least the first thermal treatment at $1060{ }^{\circ} \mathrm{C}$.

A striking observation is the formation of $\mathrm{TiO}_{2}$ nanostripes running preferentially along the [001] direction in the Pt-decorated samples upon annealing above $1000{ }^{\circ} \mathrm{C}$ [Figs. 2 and 4(a)]. Such narrow terraces or nanostripes are not observed when the NP-free substrate is subjected to the same thermal treatment [Fig. 4(b)]. Interestingly, the width of these nanostripes seems to be related to the size of the NPs and their spatial distribution to the interparticle distance. The average width of the $\mathrm{TiO}_{2}$ terraces on the Pt-decorated samples was $\sim 16 \mathrm{~nm}$ at $1010{ }^{\circ} \mathrm{C}, \sim 23 \mathrm{~nm}$ at $1060{ }^{\circ} \mathrm{C}(10$ $\mathrm{min}$ ), and increased to $\sim 47 \mathrm{~nm}$ at $1060{ }^{\circ} \mathrm{C}(20 \mathrm{~min})$. For comparison, at $1030{ }^{\circ} \mathrm{C}$, a larger average terrace width of $\sim 80 \mathrm{~nm}$ was measured for the Pt-free $\mathrm{TiO}_{2}(110)$ support. In addition, the ratio of the length of [001] to [11ㅣ steps was much higher for the Pt-decorated surface $(\sim 11)$ as compared to pristine $\mathrm{TiO}_{2}(\sim 2.4)$. From the analysis of multiple 200 $\times 200 \mathrm{~nm}^{2}$ STM images of our $\mathrm{Pt} / \mathrm{TiO}_{2}$ system, a strong decrease in the total length of the steps parallel to [001] was 

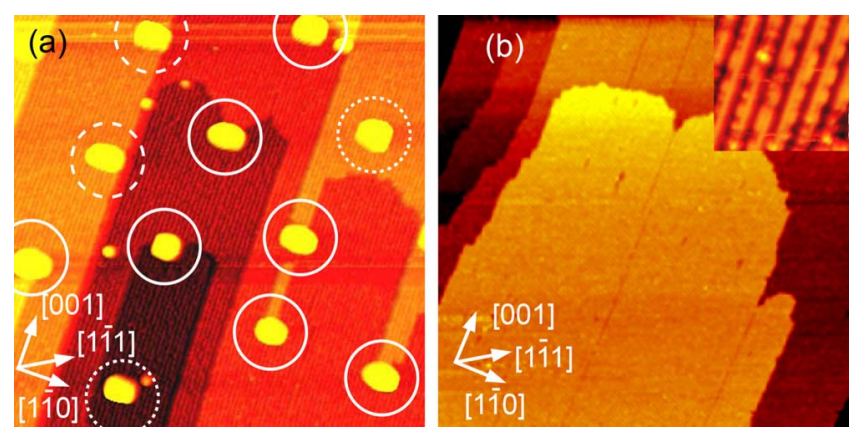

FIG. 4. (Color online) $\left(100 \times 100 \mathrm{~nm}^{2}\right) \mathrm{STM}$ images obtained on (a) $\mathrm{Pt}$ NPs deposited on $\mathrm{TiO}_{2}(110)$ and (b) the pristine $\mathrm{TiO}_{2}(110)$ substrate after annealing at 1060 and $1030{ }^{\circ} \mathrm{C}$ for $10 \mathrm{~min}$, respectively. Insert in (b): $\left(7 \times 7 \mathrm{~nm}^{2}\right)$ region of the atomically resolved $\mathrm{TiO}_{2}$ surface. The circles in (a) indicate the presence of NPs at different sites: (1) on the center of $\mathrm{TiO}_{2}$ terraces (dotted), (2) on steps parallel to the [001] direction (dashed), (3) NPs at the end of $\mathrm{TiO}_{2}$ nanostripes, or at $[1 \overline{1} 1]$ steps (full).

observed with increasing annealing temperature. Measured lengths ranged from $\sim 2430 \mathrm{~nm}$ at $1010{ }^{\circ} \mathrm{C}$ to $\sim 1730$ and $\sim 853 \mathrm{~nm}$ for the 10 and $20 \mathrm{~min}$ annealing treatments at $1060{ }^{\circ} \mathrm{C}$, respectively. A similar analysis revealed significantly shorter lengths for the steps parallel to [1i1], with $\sim 227 \mathrm{~nm}$ at $1010{ }^{\circ} \mathrm{C}, \sim 130 \mathrm{~nm}$ at $1060{ }^{\circ} \mathrm{C}(10 \mathrm{~min})$, and $\sim 236 \mathrm{~nm}$ at $1060^{\circ} \mathrm{C}(20 \mathrm{~min})$.

Surprisingly, the $\mathrm{TiO}_{2}$ stripes and steps were found to be rather straight, and a large population of the $\mathrm{TiO}_{2}$ stripes was found to have one NP at the end. Statistics of the location of the Pt NPs in our samples after annealing (averaging 340 690 NPs at each temperature) revealed that $45 \%$ of the NPs are located at the end of stripes at steps parallel to [111] at $1000{ }^{\circ} \mathrm{C}$ [white circles in Fig. 4(a)], while at $1060{ }^{\circ} \mathrm{C}(20$ $\min )$ they tend to be located on the middle of terraces $(40 \%$ versus $25 \%$ at this location at $1000{ }^{\circ} \mathrm{C}$ ). Since the initial NP arrangement was preserved, this result is not attributed to the migration of Pt NPs to those step sites, but to the mobility of $\mathrm{Ti}-\mathrm{O}$ molecules or Ti and $\mathrm{O}$ atoms in the support. Berko et $a l .{ }^{11}$ reported that $\mathrm{Pt}$ atoms activate the separation of $\mathrm{Ti}_{x} \mathrm{O}_{y}$ compounds and a preferential atomic diffusion along [001] was described. Besides, our data reveal that the bonding between the Pt atoms and the $\mathrm{TiO}_{2}$ substrate is strongest at step sites. ${ }^{11}$ Sample annealing at our highest temperature $\left(1060{ }^{\circ} \mathrm{C}, 20 \mathrm{~min}\right)$ resulted in a rupture of the connection between many of our NPs and the $\mathrm{TiO}_{2}$ nanostripes, leading to the increase in the $\mathrm{TiO}_{2}$ terrace width.

The observations made here are markedly different from existing studies on UHV-grown NPs deposited on $\mathrm{TiO}_{2}$ surfaces, ${ }^{12-16}$ which showed preferential step decoration and NP coarsening at relatively low temperatures. The high stability of our micellar $\mathrm{Pt} / \mathrm{TiO}_{2}(110)$ system may be the result of our unique synthesis procedure, structure, and morphol- ogy. For example, the initial $\mathrm{O}_{2}$-plasma treatment to which our NPs were exposed results in the presence of $\mathrm{O}$-adatoms on the $\mathrm{TiO}_{2}(110)$ surface, and stronger bonding of metal NPs to such a surface has been previously reported. ${ }^{17}$ Alternatively, small amounts of carbon (not detectable by XPS) might be present underneath the NPs or at the NP/support perimeter in the form of $\mathrm{TiC}$ compounds that could contribute to the stabilization of the NPs. Furthermore, in contrast with UHV evaporated NP samples, our size-selected threedimensional-like spherical NP samples have relatively large interparticle distances and $\mathrm{Pt}$ atoms or small $\mathrm{Pt}$ seeds are not present between larger NPs, making Ostwald ripening processes less favorable.

In summary, we demonstrated high thermal stability and enhanced particle-support adhesion of Pt NPs prepared by micelle encapsulation on $\mathrm{TiO}_{2}$. No mobility (as a whole or through Ostwald ripening) is observed up to at least $1060{ }^{\circ} \mathrm{C}$. Significant substrate surface restructuring is observed at annealing temperatures above $1000^{\circ} \mathrm{C}$, leading to the formation of $\mathrm{TiO}_{2}$ nanostripes with a width that appears to be affected by the NP size. This type of micelle-generated particle array may lead to high-temperature nanocatalysts with tunable substrate structure.

This work was supported by the U.S. Department of Energy (Grant No. DE-FG02-08ER15995).

${ }^{1}$ O. Dulub, W. Hebenstreit, and U. Diebold, Phys. Rev. Lett. 84, 3646 (2000).

${ }^{2}$ F. Pesty, H. P. Steinruck, and T. E. Madey, Surf. Sci. 339, 83 (1995).

${ }^{3}$ D. N. Belton, Y. M. Sun, and J. M. White, J. Phys. Chem. 88, 1690 (1984)

${ }^{4}$ T. Akita, K. Tanaka, S. Tsubota, and M. Haruta, J. Electron Microsc. 49, 657 (2000).

${ }^{5}$ L. K. Ono, D. Sudfeld, and B. Roldan Cuenya, Surf. Sci. 600, 5041 (2006).

${ }^{6}$ J. R. Croy, S. Mostafa, J. Liu, Y. H. Sohn, and B. Roldan Cuenya, Catal. Lett. 118, 1 (2007).

${ }^{7}$ C. R. Henry, Surf. Sci. Rep. 31, 231 (1998).

${ }^{8}$ A. S. Eppler, G. Rupprechter, E. A. Anderson, and G. A. Somorjai, J. Phys. Chem. B 104, 7286 (2000).

${ }^{9}$ K. H. Hansen, T. Worren, S. Stempel, E. Laegsgaard, M. Baumer, H. J. Freund, F. Besenbacher, and I. Stensgaard, Phys. Rev. Lett. 83, 4120 (1999).

${ }^{10}$ J. Zhang, K. Sasaki, E. Sutter, and R. R. Adzic, Science 315, 220 (2007).

${ }^{11}$ A. Berko, O. Hakkel, J. Szoko, and F. Solymosi, Surf. Sci. 507, 643 (2002).

${ }^{12}$ S. C. Parker and C. T. Campbell, Phys. Rev. B 75, 035430 (2007).

${ }^{13}$ A. El-Azab, S. Gan, and Y. Liang, Surf. Sci. 506, 93 (2002).

${ }^{14}$ M. J. J. Jak, C. Konstapel, A. van Kreuningen, J. Verhoeven, and J. W. M. Frenken, Surf. Sci. 457, 295 (2000).

${ }^{15}$ P. Stone, S. Poulston, R. A. Bennett, and M. Bowker, Chem. Commun. (Cambridge) 1998, 1369.

${ }^{16}$ X. Lai, T. P. St Clair, M. Valden, and D. W. Goodman, Prog. Surf. Sci. 59, 25 (1998).

${ }^{17}$ D. Matthey, J. G. Wang, S. Wendt, J. Matthiesen, R. Schaub, E. Laegsgaard, B. Hammer, and F. Besenbacher, Science 315, 1692 (2007). 